\title{
Patterns of acute stroke care in three districts of southern England
}

\author{
C D A Wolfe, N A Taub, J Woodrow, E Richardson, F G Warburton, P G J Burney
}

\begin{abstract}
Objective-To quantify the use of health care services by acutely ill stroke patients in three district health authorities.

Design-A follow up study of all patients recorded in population based registers who had a first ever stroke in three district health authorities, with assessment following the onset and three months after the stroke.

Setting-West Lambeth, Lewisham and North Southwark, and Tunbridge Wells District Health Authorities in south east England.
\end{abstract}

Subjects-All first time stroke patients under the age of 75 years who presented between 15 August 1989 and 14 August 1990.

Measurements and main results-Hospital admission rates, rates of use of rehabilitation services, and contact with medical practitioners together with assessment of disability and handicap were determined. A total of 386 strokes were registered. Seventy eight per cent were treated in hospital and younger and incontinent patients were significantly more likely to be admitted. The median stay was 21 days. Patients in West Lambeth, those paralysed, and those who stayed longer in hospital were more likely to receive physiotherapy. Altogether 265 patients were followed up, 117 having died within three months of the stroke. During the three months, $150(57 \%)$ had seen a hospital physician and $181(69 \%)$ their general practitioner, but $18(7 \%)$ had seen neither. Sixty seven $(26 \%)$ patients were moderately or severely disabled. Twenty seven per cent of inpatients had received no inpatient physiotherapy and $67 \%$ of all patients no outpatient physiotherapy during the three months.

Conclusions-The hospital admission rates were high, with long lengths of stay. There were significant differences in the amount of rehabilitation received in each district. This was low overall, especially for those not admitted to hospital. As expected, patients admitted for long periods were the most likely to receive therapy. Before district policies for admission and management of stroke patients can be drawn up, increased knowledge of which aspects of stroke management are effective is needed. Policies should aim to provide planned, coordinated care between hospital and the community. It is striking that many patients received no form of rehabilitation therapy.

f Epidemiol Community Health 1993; 47: 144-148
Stroke causes one in eight deaths in the United Kingdom and is one of the most common causes of severe handicap in adults. ${ }^{12}$ The prevalence of stroke is approximately $6 / 1000$, so that 1500 residents in an average health district are stroke sufferers. ${ }^{3}$ Between $40 \%$ and $75 \%$ of patients are admitted to hospital ${ }^{4-7} ; 12 \%$ of physicians' beds are occupied by stroke patients and the treatment of cerebrovascular disease consumes $4 \%$ of the National Health Service budget. ${ }^{89}$

The King's Fund criticised hospital services for stroke patients and also primary care and community services for being haphazard, fragmented, and poorly tailored to patients' needs. ${ }^{8}$ Although a declining mortality rate from stroke has been observed since the late $1950 \mathrm{~s}$, there is little evidence that this is related to improvements in hospital care. ${ }^{10}$ Randomised controlled trials of specialised stroke units have not shown any improvement in survival or disability when compared with standard hospital care. ${ }^{11} 12$ An overview of the few controlled trials suggests that good organisation of disability management does lead to a more rapid recovery of independence and more rapid discharge from hospital without any major increase in the time allocated by therapists. ${ }^{13}$

There seems to be no functional difference in outcome between patients managed at home or in hospital, although patients with more severe strokes tend to be admitted to hospital, and the benefits of hospital versus community care have not been properly evaluated. ${ }^{14}{ }^{15}$ There is some evidence that early physiotherapy is beneficial to functional recovery, and Smith et al found a slight dose response relationship between the amount of unspecified therapy given and the functional recovery in patients seen after hospital discharge. The study included only $11 \%$ of discharged patients, however, and the clinical importance of the difference is difficult to judge. ${ }^{16}$

Public health physicians require information on the burden of stroke in the community in order to negotiate contracts related to local needs with provider units. The Government's green paper, The Health of the Nation suggests that targets be set for stroke, rehabilitation of stroke survivors being a key area of interest. ${ }^{17}$ This paper reports on the current use of services by residents under the age of 75 in three districts during the first three months after a stroke, the time when patients could most benefit from health service interventions.

\section{Methods}

Stroke registers were set up to cover all the residents of West Lambeth (WL), Lewisham and North Southwark (LNS) and Tunbridge Wells 
(TW) District Health Authorities in southern England. ${ }^{18}$ Data were collected on the patients' gender, age, ethnic group, living conditions before stroke, and activities of daily living and handicap scores before stroke. Information was collected on a standardised questionnaire from either the patient, the hospital or general practitioner notes, health care workers, relatives, and coroners and post mortem reports. The activities of daily living was assessed by the research assistant using the Barthel 20 point scale ${ }^{1920}$ and handicap using the Ranking 6 point scale, with good agreement between observers..$^{21-23}$ The dates of stroke and of hospital admission and discharge, the hospital, type of hospital bed (medical, neurology, geriatric, intensive care, surgical), and any transfers to different types of bed were recorded. The severity of the stroke at the time of maximum impairment within the first 24 hours (coma, paralysis, speech, urinary or swallowing impairments), and the use of computed tomography were recorded.

The number of contacts with rehabilitation staff were recorded for the first three weeks after the stroke. Details of the number of contacts were obtained from the rehabilitation departments in all units treating district residents. Only formal contacts were recorded and not rehabilitation performed on wards by other health care professionals. No estimation of the length or content of contact was made as the study was not addressing the effectiveness of the various components of rehabilitation.

The number of rehabilitation sessions received in the first three weeks was compared between the live, non-comatose patients (that is, those for whom it would be most suitable) who were admitted to hospital and those who remained at home.

The same details and a record of changes in status were recorded at three months along with data on the number of contacts with hospital physicians, general practitioners (in surgery or domicillary), and with rehabilitation professionals (as inpatients and as outpatients). Details of any illness other than the stroke were recorded. Information on whether blood pressure had been measured and hypertension treated was obtained from patients and from outpatient and general practitioner notes. The numbers of therapy sessions received by those live and non-comatose patients during the three months are displayed for both inpatients and outpatients. The analysis is based on inpatient sessions while an inpatient and outpatient sessions while an outpatient.

\section{STATISTICAL METHODS}

Non-parametric methods were used to analyse data that were not normally distributed on lengths of stay in hospital, numbers of visits to general practitioners, and rehabilitation sessions.

The associations of various characteristics with a patient's admission to hospital and with receipt of physiotherapy, occupational or speech therapy (non-comatose patients only) were estimated by multiple logistic regression, after adjusting for age, ethnicity, and district of residence. ${ }^{24}$ When modelling for the receipt of rehabilitation services, the only additional variables considered were the length of stay in hospital and the relevant severity indicators associated with the form of rehabilitation (for example, speech/swallowing impairment for speech therapy). When modelling for admission to hospital, other variables were selected by a backwards stepwise procedure with significance set at the $5 \%$ level. The variables considered were gender, Rankin and Barthel scores before the stroke, whether living alone before the stroke, type of hospital bed, severity indicators, and the number of rehabilitation sessions. Patients who died on the day of their stroke were not included in these analyses. The unknown responses were considered as a separate category, but these categories' contribution to the regression are not interpreted. The categories of the variables selected are displayed in the relevant tables.

\section{Results}

A total of 386 first time strokes were registered during the study period.

The mean age at the time of stroke was 64.2 years. Twenty five per cent of subjects lived alone before their stroke. Twenty eight patients (7\%) were already in hospital at the time of their stroke (3 (3\%) WL, 19 (11\%) LNS, and $6(6 \%) \mathrm{TW}$; variation between districts $\left.\chi_{2}^{2}=5 \cdot 9, p=0 \cdot 05\right)$. A further $274(71 \%)$ patients were admitted to hospital and $83(22 \%)$ were not admitted. Thirty two deaths $(25 \%$ of all deaths) occurred on the same day as the stroke.

Two hundred and twenty six hospital admissions $(83 \%)$ were on the same day as the stroke, with no significance between districts. Younger patients and those with incontinence were more likely to be admitted to hospital and there was no apparent difference in admission rates between districts.

Patients were admitted to 28 hospitals. Lengths of stay in hospital varied from 1 to 264 days with a median of 21 days and showed no significant difference between the districts (Kruskal-Wallis test, $\mathrm{p}=0 \cdot 10$ ).

Of the WL residents who suffered a stroke, 49 $(50 \%)$ were admitted to the local district hospital and $17(17 \%)$ to neighbouring district hospitals. Of the LNS residents, $115(64 \%)$ were admitted to the two district hospitals and $20(11 \%)$ to neighbouring district hospitals. Of the TW patients, $75(69 \%)$ were admitted to the two local district hospitals and $3(3 \%)$ to neighbouring district hospitals

Overall, $239(79 \%)$ of the hospital admissions were to medical beds, $34(11 \%)$ to geriatric, 12 $(4 \%)$ to intensive care, and $4(1 \%)$ to neurology beds.

On the day of the stroke $77(20 \%)$ patients were in a coma. Of those who were conscious and survived the first day $298(76 \%)$ had a paralysis or weakness, $226(59 \%)$ had a speech impairment, $103(27 \%)$ a swallowing impairment, and 132 (34\%) were incontinent or had a urinary catheter.

Overall, $69 \%$ of patients admitted to hospital received some physiotherapy in the first three weeks and there was a significant difference between the districts $\left(\chi_{2}^{2}=15 \cdot 5, p<0 \cdot 001\right)$. For those patients who received physiotherapy the median number of sessions was $3 \cdot 3$ per week, with a significant difference between districts (KruskalWallis test, $p=0.002$ ). There was no significant difference between districts in the proportions of 
patients who received occupational or speech therapy; the median number of sessions for these patients were 1.7 and 1 session per week respectively.

Eleven of $57(19 \%)$ patients not admitted to hospital received physiotherapy and had a median of two sessions per week during the first three weeks. Four per cent received occupational therapy and none received speech therapy during this period.

ASSESSMENT THREE MONTHS AFTER STROKE Two hundred and sixty five patients were assessed three months after their stroke. Altogether 117 had died and three were lost to follow up (two had moved abroad). Forty two (16\%) were still in hospital and there was no significant difference between the districts $\left(\chi_{2}^{2}=2 \cdot 3, p>0 \cdot 1\right)$. One hundred and seventy seven patients $(67 \%)$ were living with another person, $39(15 \%)$ were living alone,

Table I Rankin handicap score measured three months after stroke in the three health districts

\begin{tabular}{llllll}
\hline Handicap & Score & $\begin{array}{l}\text { West } \\
\text { Lambeth }\end{array}$ & $\begin{array}{l}\text { Lewisham E } \\
\text { N Southwark }\end{array}$ & $\begin{array}{l}\text { Tunbridge } \\
\text { Wells }\end{array}$ & All 3 \\
\hline $\begin{array}{l}\text { Functionally } \\
\text { independent }\end{array}$ & $0,1,2$ & $36(57 \%)$ & $76(61 \%)$ & $54(74 \%)$ & $166(64 \%)$ \\
$\begin{array}{l}\text { Moderate } \\
\text { Severe }\end{array}$ & 3 & $10(16 \%)$ & $21(17 \%)$ & $12(16 \%)$ & $43(16 \%)$ \\
& $\{4$ & $14(22 \%)$ & $18(14 \%)$ & $4(5 \%)$ & $36(14 \%)$ \\
5 & $3(5 \%)$ & $10(8 \%)$ & $3(4 \%)$ & $16(6 \%)$ \\
\hline
\end{tabular}

4 patients were not assessed

Table II Barthel disability score measured three months after stroke in the three health districts

\begin{tabular}{llllll}
\hline Disability & Score & $\begin{array}{l}\text { West } \\
\text { Lambeth }\end{array}$ & $\begin{array}{l}\text { Lewisham E } \\
\text { N Southwark }\end{array}$ & $\begin{array}{l}\text { Tunbridge } \\
\text { Wells }\end{array}$ & \multicolumn{1}{l}{ All 3} \\
\hline None & 20 & $33(52 \%)$ & $56(45 \%)$ & $49(67 \%)$ & $138(53 \%)$ \\
Mild & $15-19$ & $12(19 \%)$ & $29(23 \%)$ & $15(21 \%)$ & $56(21 \%)$ \\
Moderate/Severe & $0-14$ & $18(29 \%)$ & $40(32 \%)$ & $9(12 \%)$ & $67(26 \%)$ \\
\hline
\end{tabular}

4 patients were not assessed

Table III Inpatient and outpatient rehabilitation therapy rates during the first three months (sessions per week), for patients who survived the day of stroke without being in coma

\begin{tabular}{|c|c|c|c|c|c|c|}
\hline & $\begin{array}{l}\text { Total } \\
\text { no. of } \\
\text { patients }\end{array}$ & $\begin{array}{l}\text { No. } \\
\text { with } \\
\text { therapy }\end{array}$ & $\begin{array}{l}\% \\
\text { with } \\
\text { therapy }\end{array}$ & $\begin{array}{l}\chi^{2} \\
p \text { value }\end{array}$ & $\begin{array}{l}\text { Median } \\
\text { sessions } \\
\text { per week } \\
\text { for those } \\
\text { receiving } \\
\text { therapy }\end{array}$ & $\begin{array}{l}\text { Kruskal- } \\
\text { Wallis } \\
\text { p value }\end{array}$ \\
\hline $\begin{array}{l}\text { While an inpat } \\
\text { Physio: all } 3 \\
\text { WL } \\
\text { LNS } \\
\text { TW }\end{array}$ & $\begin{array}{r}251 \\
58 \\
122 \\
71\end{array}$ & $\begin{array}{r}182 \\
53 \\
87 \\
42\end{array}$ & $\begin{array}{l}73 \\
91 \\
71 \\
59\end{array}$ & $\begin{array}{l}\chi_{2}^{2}=16.8 \\
p<0.001\end{array}$ & $\begin{array}{l}3 \cdot 5 \\
3 \cdot 4 \\
4 \cdot 1 \\
3 \cdot 0\end{array}$ & $\mathrm{p}=0.008$ \\
\hline $\begin{array}{l}\text { OT: all } 3 \\
\text { WL } \\
\text { LNS } \\
\text { TW }\end{array}$ & $\begin{array}{r}251 \\
58 \\
122 \\
71\end{array}$ & $\begin{array}{r}139 \\
36 \\
70 \\
33\end{array}$ & $\begin{array}{l}55 \\
62 \\
57 \\
46\end{array}$ & $\begin{array}{l}\chi_{2}^{2}=3.5 \\
p>0.1\end{array}$ & $\begin{array}{l}1.5 \\
1.5 \\
1.9 \\
1.7\end{array}$ & $p>0.1$ \\
\hline $\begin{array}{l}\text { Speech: all } 3 \\
\text { WL } \\
\text { LNS } \\
\text { TW }\end{array}$ & $\begin{array}{r}185 \\
36 \\
93 \\
56\end{array}$ & $\begin{array}{l}95 \\
21 \\
51 \\
23\end{array}$ & $\begin{array}{l}51 \\
58 \\
55 \\
41\end{array}$ & $\begin{array}{l}\chi_{2}^{2}=3 \cdot 5 \\
\mathrm{p}>0 \cdot 1\end{array}$ & $\begin{array}{l}0 \cdot 9 \\
1 \cdot 4 \\
1 \cdot 3 \\
0 \cdot 8\end{array}$ & $p=0.02$ \\
\hline $\begin{array}{l}\text { While an outpo } \\
\text { Physio: all } 3 \\
\text { WL } \\
\text { LNS } \\
\text { TW }\end{array}$ & $\begin{array}{r}234 \\
59 \\
106 \\
69\end{array}$ & $\begin{array}{l}78 \\
17 \\
41 \\
20\end{array}$ & $\begin{array}{l}33 \\
29 \\
39 \\
29\end{array}$ & $\begin{array}{l}\chi_{2}^{2}=2 \cdot 5 \\
\mathrm{p}>0.1\end{array}$ & $\begin{array}{l}0 \cdot 7 \\
0 \cdot 6 \\
0 \cdot 7 \\
0 \cdot 6\end{array}$ & $p>0.1$ \\
\hline $\begin{array}{l}\text { OT: all } 3 \\
\text { WL } \\
\text { LNS } \\
\text { TW }\end{array}$ & $\begin{array}{r}234 \\
59 \\
106 \\
69\end{array}$ & $\begin{array}{r}28 \\
10 \\
10 \\
8\end{array}$ & $\begin{array}{r}12 \\
17 \\
9 \\
12\end{array}$ & $\begin{array}{l}\chi_{2}^{2}=2 \cdot 04 \\
p>0.1\end{array}$ & $\begin{array}{l}0 \cdot 4 \\
0 \cdot 8 \\
0 \cdot 3 \\
0 \cdot 9\end{array}$ & $p=0.03$ \\
\hline $\begin{array}{l}\text { Speech: all } 3 \\
\text { WL } \\
\text { LNS } \\
\text { TW }\end{array}$ & $\begin{array}{r}160 \\
30 \\
80 \\
50\end{array}$ & $\begin{array}{r}25 \\
4 \\
12 \\
9\end{array}$ & $\begin{array}{l}16 \\
13 \\
15 \\
18\end{array}$ & $\begin{array}{l}\chi_{2}^{2}=0.36 \\
p>0.1\end{array}$ & $\begin{array}{l}0 \cdot 4 \\
0 \cdot 5 \\
0 \cdot 6 \\
0 \cdot 3\end{array}$ & $p>0.1$ \\
\hline
\end{tabular}

OT=occupational therapy; physio=phsyiotherapy; speech=speech therapy Data for speech therapy apply only to patients with speech and/or swallowing impair
WL=West Lambeth; LNS=Lewisham and North Southwark; TW=Tunbridge Wells and $5(2 \%)$ were in residential care. Of those initially living alone $36(54 \%)$ were still alone and $18(27 \%)$ were still in hospital with no significant district difference $\left(\chi_{2}^{2}=0 \cdot 8, \mathrm{p}>0 \cdot 1\right)$.

One hundred and eleven (42\%) patients had received medical care for a condition other than the stroke but only $17(6 \%)$ had been admitted to hospital for that condition. One hundred and fifty $(57 \%)$ patients had seen a physician or geriatrician-with 97 as outpatients, 51 as inpatients, and only two as a domiciliary visit. Of the 83 patients not admitted to hospital at the time of their stroke 54 were alive at three months, and of these $20(37 \%)$ had seen a physician as an outpatient. Thirty four (13\%) of the patients who survived to follow up were neither admitted to hospital nor seen by a hospital doctor, 18 (7\%) were followed up by neither a GP nor a hospital doctor.

The Rankin and Barthel scores at three months are given in tables I and II. One hundred and thirty five patients $(53 \%)$ had no change in their Barthel score compared with the assessment of their status before the stroke, $59(23 \%)$ had a worsening of 1 to 5 points, and $49(19 \%)$ a worsening of 6 to 15 points. Overall, $76(30 \%)$ had no change in the Rankin score; 54 (21\%) showed a worsening of 1 point, 47 (18\%) 2 points, 36 (14\%) 3 points, 25 $(10 \%) 4$ points, and $11(4 \%) 5$ points, with $8(3 \%)$ having an improvement in their handicap score.

Seventy three per cent of patients had received some inpatient physiotherapy during the three months and there was a highly significant variation between the districts. The rate for physiotherapy as an outpatient was only $33 \%$, with no apparent difference between the districts (table III).

Patients in West Lambeth, paralysed patients, and those with longer lengths of stay in hospital were more likely to receive physiotherapy (table IV). Patients with longer lengths of stay and those who were paralysed but not incontinent were more likely to receive occupational therapy. Speech therapy was more likely to be received by long stay patients and those with a speech impairment.

Overall, 181 patients $(69 \%)$ had seen their GP since the stroke (WL $65 \%$, LNS $63 \%$, and TW $82 \%)$ and there was a significant difference between districts $\left(\chi_{2}^{2}=8 \cdot 0, p=0 \cdot 02\right)$. The mean number of surgery visits was 1.3 during three months, with a significant difference between districts (WL $1 \cdot 5$, LNS 0.9, TW $1 \cdot 7$, KruskalWallis test, $\mathrm{H}=19 \cdot 3, \mathrm{p}<0.001)$.

Fifty eight pateints $(89 \%)$ in WL, $98(78 \%)$ in LNS, and $62(86 \%)$ in TW had their blood pressure recorded during the first three months, with no variation between districts $\left(\chi_{2}^{2}=4 \cdot 7\right.$, $\mathrm{p}=0.09)$. Overall, $127(48 \%)$ patients were diagnosed as hypertensive and $125(98 \%)$ of these were on antihypertensive treatment.

At three months, $75(28 \%)$ patients still had a speech impairment, and of these 10 had no other impairment, $18(7 \%)$ had a swallowing impairment, $26(10 \%)$ were incontinent or catheterised, and two patients were still in semi-coma but had not had a recurrence of stroke. One hundred and eighty one patients $(68 \%)$ were paralysed or had a weakness. There was no significant difference between districts for any of these measures of severity. 
Table IV Multiple logistic regression model to predict which patients receive physiotherapy within three months of their stroke in the three health districts

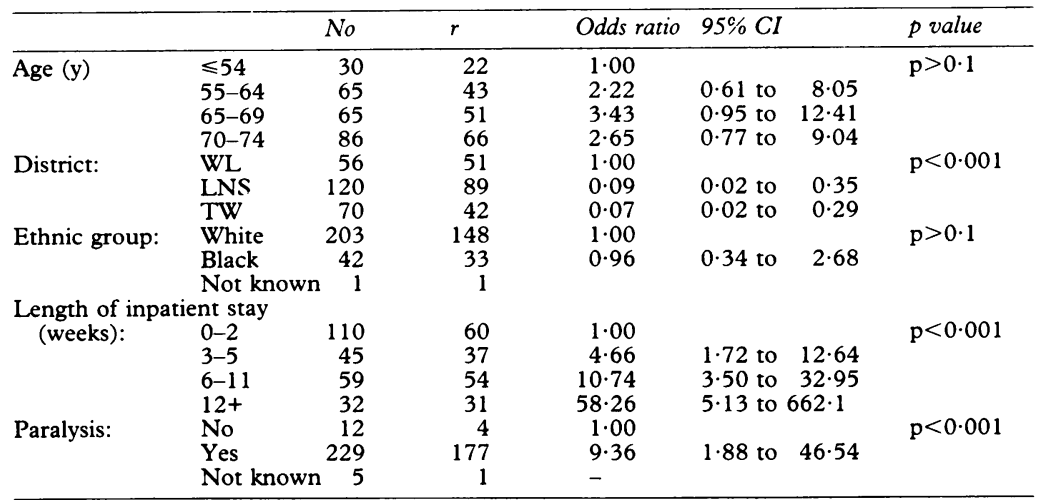

WL=West Lambeth; LNS=Lewisham and North Southwark; TW=Tunbridge Wells No=total number of patients in category

$\mathrm{r}=$ number of these who receive physiotherapy

Restricted to those admitted to hospital, live and not initially comatose

\section{Discussion}

Health services for patients who have suffered a stroke cost an average district health authority an estimated three million pounds per annum. ${ }^{8}$ This estimate is considered conservative as long term and respite care are not included in these costs. Despite the magnitude of the problem there seem to be deficiencies in the provision of services to this group of patients which both the purchasers and providers of health care should consider when drawing up contract specifications. ${ }^{8}{ }^{9}$ There has been no comprehensive audit of stroke services undertaken in the United Kingdom and this study examines stroke service provision in the acute phase of the illness in residents aged under 75 years, a group which is the focus of the government's targets for stroke. ${ }^{17}$ For a condition that consumes a considerable proportion of health service resources there has been little evaluation of the effectiveness of the services provided for treating it.

This was a large study, encompassing a population of over 600000 district residents. To encourage registration of strokes, several sources of notification were used and feedback to health care professionals was on a regular basis. We have already estimated the incidence and case fatality of stroke in the under $75 \mathrm{~s}$ in these districts ${ }^{18}$ but this paper is concerned with the utilisation of health services in these groups. We are confident that the case ascertainment methods used provide us with an accurate picture in the three health districts.

The hospital admission rate of $78 \%$ is higher than that previously quoted, ${ }^{57}$ which may reflect a lack of community based rehabilitation and nursing services in the districts under study. Admission to hospital is often for social and nursing reasons, ${ }^{7}$ consequently hospital may not be the most appropriate place for these patients. A quarter of all patients were living alone before their stroke, however, and this may be a good reason for admission. There seems to be no difference in admission rates between rural TW and the inner city districts but younger patients and those who were incontinent as a result of their stroke were more likely to be admitted. The appropriateness of these admissions was not assessed independently in this study. In a World Health Organisation study ${ }^{5}$ similar hospital admission rates within the first 24 hours of a stroke were reported and a similar proportion of strokes occurred to patients while in hospital but in this study LNS had significantly more strokes occurring in postoperative cardiac patients.

The median length of stay in hospital of three weeks is twice that reported in Bristol and represents a considerable proportion of physicians' bed days for a condition where the appropriateness of admission is questioned for many patients. ${ }^{6}$ Local district general hospitals managed only between $50 \%$ and $70 \%$ of their residents and in future purchasers of stroke services should be seeking comprehensive district provision to allow for continuity of care between hospital and the community, although this may be unrealistic in inner city districts.

A detailed clinical audit of the medical process was not carried out in the three districts as districts and units had not developed agreed standards of care or a stroke policy with which the results could be compared. These data do, however, provide a baseline for audit. Subsequent to these results having been brought to the attention of local health care professionals, standards and objectives in two of the districts have been formulated. ${ }^{25}$

There is some evidence that early rehabilitation is beneficial to functional recovery, although most of the functional gains experienced by stroke patients are probably attributable to spontaneous recovery. Rehabilitation may, however, result in increased independence in the performance of activities of daily living for patients who have intermediate levels of functional ability. ${ }^{15} 16$ The analysis of rehabilitation received, restricted to those patients eligible to receive it, illustrates major deficiencies and some significant variation between districts in the provision of these services, especially for patients in the community. Thirty one per cent of patients received no physiotherapy in the first three weeks. This may be because of a lack of services, poor communication, a belief that therapy has no effect on functional outcome, or because there was no clinical indication. Those outpatients who received physiotherapy received a median of less than one session per week and longer stay inpatients were the most likely to receive therapy.

There was significant variation between districts in the use of physiotherapy. In the district which during the study period started to have weekly multidisciplinary meetings to plan stroke care, over $90 \%$ received some physiotherapy. There were no district differences for occupational and speech therapy but the overall proportion of patients who received sessions was low in comparison with the prevalence of disability. These results are not surprising when the low staffing levels in the rehabilitation departments involved in the study, especially in the community, are considered.

The data display very low rehabiliation rates compared with the Bristol study of 1984 in which an average of 46 minutes therapy a day were recorded over the first six months of therapy, but neither study included the therapy learnt and practised by the patients on their own. ${ }^{15}$ With a median of one session per week of physiotherapy recorded in this study, the government's suggestion that targets be set for the rehabilitation of stroke patients should be developed further. The 
effectiveness of the rehabilitation provided should be evaluated, however, alongside the development of these targets. The study did not explore how appropriately rehabilitation therapy was distributed but concurs with previous studies showing that therapy is more intense for those with the more severe strokes ${ }^{14}$ and that research is required to determine which components of rehabilitation are effective, and at what intensity.

A planned discharge from hospital with community care after expensive, long lengths of stay in hospital is considered an important part of good stroke care. ${ }^{8}$ Patients were followed up in hospital outpatient clinics in only $55 \%$ of cases. Only $69 \%$ had seen their GP since their stroke, with a significantly higher proportion being seen by their GP in rural TW. As $7 \%$ of patients saw neither a GP nor a hospital doctor after discharge from hospital or after diagnosis at home, targets could be set to address this issue of continuity of care and be audited both in hospital and in primary care.

The levels of impairment and handicap at three months were similar to those in other studies. ${ }^{24} 27 \cdot 30$ The level of speech impairment was higher than previously quoted but this study did not undertake a detailed neurological assessment of the speech impairment. Of more importance are the resultant levels of disability and handicap, which are similar to those in British studies, ${ }^{27} 2830$ with $45 \%$ of patients being either moderately or severely disabled after their stroke. These data illustrate the need for support services for this group of patients.

These data illustrate the pattern of care for stroke in those aged under 75 years in a population of 620000 . There is a high admission rate to hospital with long lengths of stay but with no planned, coordinated follow up in the community. The King's Fund has advocated the evaluation of different forms of care for stroke patients to overcome the haphazard, fragmented, and poorly tailored services. This report supports the need to assess different packages of care and to develop targets for stroke management and rehabilitation.

We wish to thank the Chest Heart and Stroke Association and the Department of Health for funding. We are most grateful to all those who notified the register of cases, especially those in the community. Our thanks to Ana Childs for typing the manuscript.

1 Office of Population Censuses and Surveys. Mortality statistics cause. England and Wales. London: HMSO, 1991 statistics cause. England ar
(Series DH2, No 17).

2 Martin J, White A, Meltzer H. Office of Population Censuses and Surveys. Disabled adults: services transport and employment ((Report 4) Disability in Great Britain). London: HMSO, 1989.

3 Kurtze JF. The current neurologic burden of illness and injury in the United States. Neurology 1982; 32: 1207-14.
4 Brocklehurst C, Andrews K, Morris P, Richards BR, Laycock PJ. Why admit stroke patients to hospital? Age and Ageing 1978; 7: 100-8.

5 Aho K, Harmsen P, Hatomo S, Marquardsen J, Smirnov VE, Strasser $T$. Cerebrovascular disease in the community: results of a WHO collaborative study. Bull WHO 1980; 8(i): 113-30.

6 Wade DT, Langton Hewer R. Hospital admission for acute stroke: who, for how long, and to what effect? $\mathcal{F}$ Epidemiol Community Health 1985; 39: 347-52.

7 Bamford J, Sandercock P, Warlow C, Gray M. Why are patients with acute stroke admitted to hospital? $B M F$ 1986; 1: $1369-72$.

8 King's Fund Consensus statement. The treatment of stroke. BMF 1988; 297: 126-8.

9 Office of Health Economics. Stroke. London: Office of Health Economics, 1988 Series No 89.

10 Gillum RF, Gromez-Martin O, Kottbe E, Jacobs DR et al. Acute stroke in a metropolitan area. 1970 and 1980. The Minnesota Heart Study. Fournal of Chronic Diseases 1985; 38: 891-8.

11 Garraway WM, Akhtar AJ, Hockey L, Prescott RJ. Management of acute stroke in the elderly: follow-up of a controlled trial. BMF 1980; 281: 827-9.

12 Stevens RS, Ambler NR, Warren MD. A randomized controlled trial of a stroke rehabilitation ward. Age and Ageing 1984; 13: 65-75.

13 Ebrahim S. Clinical epidemiology of stroke. Oxford: Oxford University Press, 1990

14 Wade DT, Langton Hewer R, Skilbeck CE, Bainton D, Burns Cox C. Controlled trial of a home care service for acute stroke patients. Lancet 1985; ii: 323-6.

15 Wade DT, Skilbeck CE, Langton Hewer R, Wood VA. Therapy after stroke: amounts, determinants and effects. International Rehabilitation Medicine 1984; 6: 105-110.

16 Smith DS, Goldenberg E, Ashburn A. Remedial therapy after stroke: a randomized controlled trial. $B M \mathcal{F} 1981 ; 282$ : 517-20.

17 Secretary of State for Health. The health of the nation: a consultative document for health in England. London: HMSO, 1991. (Cmnd 1523)

18 Wolfe CDA, Taub NA, Woodrow J, Richardson E, Warburton FG, Burney PGJ. Does incidence, severity or case-fatality of stroke vary in Southern England. 7 Epidemiol Community Health 1993; 47: 139-143.

19 Mahoney FI, Barthel DW. Functional evaluation. The Barthel index. Maryland State Medical fournal 1965; 14: 61-5.

20 Collins C, Wade DT, Davis S, Horne V. The Barthel ADL index: a reliability study. International Disabilities Studies 1968; 10: $61-3$.

21 Rankin R. Cerebral vascular accidents in patients over 60. II Prognosis. Scott Med f 1957; 2: 200-5.

22 van Swieton JC, Koudstaal PJ, Visser MC, Schouten HJA, van Gijn J. Interobserver agreement for the assessment of handicap in stroke patients. Stroke 1988; 19: 604-7.

23 Wolfe CDA, Taub NA, Woodrow EJ, Burney PGJ. Assessment of scales of disability and handicap for stroke patients. Stroke 1991; 22: 1242-4.

24 Dixon WJ, BMDP Statistical software manual. Volume 2. Berkeley: University of California Press, 1990; 739-806.

25 West Lambeth Health Authority Stroke Steering Group. Setting district stroke standards and objectives. $\mathcal{F}$ Roy Coll Physicians Lond 1992; 26: 172-6.

26 Brocklehurst JC, Andrews K, Richards B, Laycock P. How much physical therapy for patients with a stroke? $B M F 1978$; 1: $1307-10$.

27 Malmgren R, Bamford J, Warlow C, Sandercock P, Slattery $J$. Projecting the number of patients with first ever strokes and patients newly handicapped by stroke in England and Wales. BMF 1989; 298: 656-60.

28 Wade DT. Langton Hewer R. Functional abilities after stroke: measurement, natural history and prognosis. $\mathcal{f}$ stroke: measurement, natural history and prog

29 Wade DT, Langton Hewer R, David RM, Enderby PM. Aphasia after stroke: natural history and associated deficits. Aphasia after stroke: natural history and associated

30 Bamford J, Sandercock P, Dennis M, Burn J, Warlow C. A Bamford J, Sandercock P, Dennis M, Burn J, Warlow C. A
prospective study of acute cerebrovascular disease in the prospective study of acute cerebrovascular disease in the
community. The Oxfordshire Community Stroke community. The Oxfordshire Community Stroke
Project-1981-86. 2. Incidence, case fatality rates and Project-1981-86. 2. Incidence, case fatality rates and intracerebral and subarachnoid haemorrhage. $\mathcal{F}$ Neurol Neurosurg Psychiatry 1990; 53: 16-22. 